\title{
Reestruturação departamental da FMRP-USP
}

"Mudanças estruturais requerem, invariavelmente, interesse, disposição e motivação, entendendo-se este último substantivo, às vezes, como um certo empurrão".

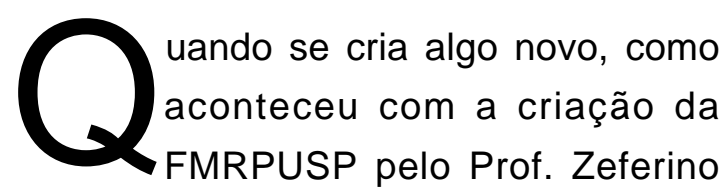
Vaz, propostas inovadoras são mais facilmente aceitas e menos questionáveis. Acredito não haver dúvidas quanto ao fato de que a "Casa de Arnaldo" (FMUSP) tenha sido um espelho para a criação da nossa Faculdade de Medicina de Ribeirão Preto. Entretanto, a nossa Faculdade veio, em 26 de dezembro de 1951, com uma modernização na sua conceituação departamental, apesar de ainda alicerçada em disciplinas. Para exemplificar, aqui foram criados apenas um (1) Departamento de Clínica Médica e um (1) de Cirurgia, em contraposição à cultura vigente à época, de fragmentação de disciplinas em várias cátedras. Estes são, apenas, dois exemplos dentre outros. Isto, sem sombra de dúvidas, resultou na criação de uma nova Faculdade de Medicina com uma estrutura mais enxuta.

No ocaso da década de sessenta (60), ou seja, em 1969, a USP promoveu a sua grande reforma estatutária; extinguiu as cátedras, instituiu os Conselhos Departamentais, reduziu o número de departamentos das suas unidades, mas não limitou o número de docentes para constituição de um departamento. Esta estrutura se manteve de 1969 até maio de 1996 (Resolução 4264) quando o Conselho Universitário, com base em dados estatísticos discutíveis, é verdade, deliberou estabelecer o número mí- nimo de quinze (15) docentes para a permanência de um departamento. É verdade, também, que tal resolução permitia a existência temporária de departamentos com dez (10) a quinze (15) docentes, dependendo do desempenho favorável junto à Comissão Permanente de Avaliação (CPA).

A nossa Faculdade de Medicina foi afetada pela Resolução 4264, por ter oito (8) departamentos com menos de quinze (15) docentes, sendo cinco (5) destes com obrigatoriedade de reestruturação, por força de um desempenho desfavorável junto à CPA. Em agosto de 1998, por solicitação dos Departamentos da Área Básica, a Diretoria da FMRP nomeou uma comissão para discutir soluções coletivas de reestruturação desta área. Após ouvir ilustres colegas da Faculdade de Medicina da USP (FMUSP), Instituto de Ciências Biomédicas da USP, Faculdade de Ciências Médicas de Campinas, a Presidenta da CAA (Comissão de Atividades Acadêmicas) e o Pró - Reitor de Pesquisa da USP, dentre outros, pode-se dizer, com tranqüilidade, que a principal conclusão a que se chegou foi de que, qualquer reestruturação departamental que viesse a ser feita na FMRP, esta deveria manter unidas as suas Áreas Básica e de Aplicação (Clinicocirúrgica). Aliás, isto ficou muito claro nas falas dos palestrantes da FMUSP e da Faculdade de Ciências Médicas de Campinas.

Efetivamente, o Processo de Reestruturação Departamental se iniciou em meados de outubro de 1998, com a instalação de uma Comissão de Reestruturação Departamental 
Assessora à Comissão de Assuntos Universitários (CAU) da FMRP, a qual contava com representantes de todos os departamentos da unidade. Após ouvir cerca de dois terços dos docentes da nossa Faculdade de Medicina, Comissão Assessora propôs para a Área Básica a constituição de três novos departamentos, ou sejam, Estrutura e Função de Órgãos e Sistemas, Biologia Celular e Molecular e Genética, este último com a integração dos demais geneticistas do Campus. Temporariamente, por prerrogativa do desempenho favorável junto à CPA, ficaria mantido com menos de quinze (15) Docentes o Departamento de Farmacologia. Quanto aos departamentos clínicos, a sua maioria possuía um número de docentes maior do que quinze (15) e, portanto, não necessitava de reestruturação, com exceção dos Departamentos de Oftalmologia e Otorrinolaringologia e Medicina Social.; estes Departamentos deveriam encontrar soluções acadêmicas para atender à Resolução 4264. O Departamento de Patologia, por prerrogativa do desempenho favorável junto à CPA, ficaria, temporariamente, com um número de docentes menor que quinze (15). Nota-se nesta proposta uma certa ousadia no que diz respeito à Área Básica, no sentido de se criar, com os Departamentos de Estrutura e Função de Órgãos e Sistemas e Biologia Celular e Molecular, um embrião para, no futuro, abrigar os departamentos atuais em dois grandes departamentos. Estes permitiriam a interação de grupos de pesquisas afins, sem vinculação a disciplinas, e sem multiplicação da estrutura administrativa. Fica fácil entender a não vinculação a disciplinas, visto que a "nova" (já tem seis (6) anos) estrutura curricular da FMRP tem um caráter integrativo e não mais departamental, como quando da criação da Escola. Se esta solução é mais simples de ser aplicada na Área Básica, não é de todo impossível para as Áreas de Aplicação, como veremos posteriormente. Por falta de uma discussão ampla, não só entre os docentes, como também no âmbito Departamental, tal proposta não obteve a aprovação da nossa Congregação, em dezembro último, mas deixou idéias para reflexão.

Novamente, a Comissão de Reestruturação Departamental reiniciou os trabalhos, ouvindo todos os departamentos da Escola de Medicina, colhendo sugestões para uma propositura à CAU para ser, posteriormente, levada à Congregação. Ao ouvir os departamentos, duas vertentes de opiniões foram diagnosticadas; uma majoritária, nove (9) de catorze (14) departamentos propuseram que a reestruturação deveria ser restrita àqueles que tinham a obrigatoriedade, deixando aqueles que não a tinham permanecer como tal. Na outra vertente, minoritária, cinco (5) de nove (9) departamentos propuseram uma reestruturação mais radical, ou seja, redução de todos os departamentos da FMRP a três, ou sejam, um Básico, um Clínico e um Cirúrgico. Vale ressaltar que houve, até, duas propostas mais radicais, ou seja, redução para apenas dois departamentos, um Básico e um Clinicocirúrgico.

As duas vertentes podem ser interpretadas da seguinte forma. De um lado uma maioria (dois terços) que entende que a reestruturação departamental não é um problema institucional, mas sim, individual. Por outro lado, uma minoria (um terço) entendendo que, sendo a Reestruturação Departamental um processo irreversível, ela deve ser vista como um problema institucional, devendo ser tratado como tal. Uma vez que entendo que a reestruturação é um problema institucional e, portanto, a todos deve 
tocar, também entendo que a motivação - empurrão - ensejada pela reestruturação "imposta" pelo Conselho Universitário, deve ser utilizada, positivamente, no sentido de se rediscutir a nossa estrutura departamental, não mais com base em disciplinas, como as que existiam até passado não muito distante, mas, sim, em afinidades de pesquisa (por exemplo, Biologia Celular) e acadêmica (por exemplo, Oftalmologia, Otorrinolaringologia e Cirurgia de Cabeça e Pescoço) e, porque não, enxugando, de certa forma a estrutura administrativa. Se me perguntarem se com isso algum(ns) grupo(s) poderia(m) desaparecer; eu responderia que sim, acrescentando que, por incompetência própria. Nesta Instituição, temos dois bons exemplos de departamentos, Dermatologia e Ortopedia, que foram absorvidos, respectivamente, pela Clinica Médica e Cirurgia, com a reforma de 1969, cujos componentes não desapareceram; pelo contrário, por competência demonstrada ao longo do tempo, têm tido reconhecimento nacional (prêmios, etc.) e, inclusive, projeção internacional.

Finalizando este breve relato, acompanhado de algumas reflexões, gostaria de ressaltar que, é verdade que, pelas características das atividades hospitalares (ambulatórios, leitos, centros cirúrgicos, etc.), o Processo de Integração Departamental é mais trabalhoso nas Áreas de Aplicação do que nas Áreas Básicas, porém, também é verdade que ele é factível. Haja vista que, extra - oficialmente, se sabe que há algo neste sentido em curso na nossa Escola de Medicina. Basta motivação, interesse e disposição.

Prof. Dr. HELIO C. SALGADO

Presidente da Comissão de Restruturação

Departamental da FMRP - USP

Professor Titular do Departamento de Fisiologia 